\title{
WSCHODNIOSŁOWIAŃSKIE I POLSKIE PIEŚNI TRADYCYJNE JAKO UNIWERSALNY NOŚNIK KULTURY
}

\author{
PIOTR BRASZAK
}

\begin{abstract}
In the presented article, the author considers a rarely discussed subject of traditional song lyrics perceived as culture transmitters. Even though they are very universal and comprehensive sources in terms of cultural transmission, academics use them in scientific discourse incommensurately less frequently than other textual forms or art works from the epoch. The author analyzes traditional folk songs as texts which unfold before the reader. Their crucial value and broad possibility to understand different and interfusing realms of human activity associated with Polish and East Slavic culture are presented.
\end{abstract}

Key words: traditional songs, folk songs, Polish and East Slavic culture, culture transmitters

W niniejszym artykule chciałbym poruszyć kwestię stosunkowo mało eksploatowanego nośnika kultury, jakim są teksty pieśni tradycyjnych. Pomimo ich uniwersalności i pojemności w zakresie przekazu kulturowego, badacze sięgają do nich nieporównywalnie rzadziej niż do innych form tekstu czy szerzej - sztuki, powstałej i utrwalonej w podobnym okresie. Celem niniejszego tekstu będzie więc próba scharakteryzowania tradycyjnych pieśni ludowych przede wszystkim jako tekstu otwierającego przed odbiorcą wartość i potencjał zrozumienia różnych, wzajemnie przenikających się sfer działalności człowieka, związanych z kulturą polską i wschodniosłowiańską. Będzie to z założenia ujęcie zaledwie fragmentaryczne, zarysowujące wielość możliwości badawczych.

Ponieważ badania związane z twórczością społeczności tradycyjnych znajdują się na peryferiach głównego nurtu literaturoznawstwa, należałoby dodatkowo doprecyzować rozumienie terminu pieśni ludowe. Definicję, do której chciałbym się od- 
wołać sformułował Piotr Grochowski. Według jego słów „ludowości nie należy utożsamiać $\mathrm{z}$ wiejskością: ludowy to - w opozycji do uczonego - powszechnie znany wśród ludności niewykształconej, przekazywany ustnie a nie pisemnie"1. Z tego też względu popularną pośród badaczy praktyką jest korzystanie z relacji ustnych lub odręcznie spisywanych zeszytów z tekstami pieśni. W związku z powyższą definicją, do zasobu analizowanych w moich badaniach tekstów wchodzą również te tworzone przez wykształcone warstwy społeczeństwa (najczęściej przez duchowieństwo), lecz w późniejszym okresie zmieniane, przetwarzane lub po prostu rozumiane w niezależny sposób przez samych wykonawców - lud. Jacek Kolbuszewski uważał również, że „precyzyjne wyznaczenie granicy między tekstami 'sfolkloryzowanymi' a stricte 'kościelnymi' jest niemal niemożliwe", , a „akceptacja tekstu nie stanowi [...] o ludowym sposobie pojmowania śmierci”’ Skłaniam się również ku rozumieniu terminu pieśni $w$ szerszym kontekście, jako tekst kultury, złożony nie tylko z samej warstwy słownej, ale i z gestów czy czynności im towarzyszących, dopełniających znaczenie samego utworu i będących składowymi elementami obrzędowych ceremonii. Podejście to jest naukowo efektywne, zwłaszcza w przypadku grupy pieśni pogrzebowych, w których towarzyszące śpiewom rytuały miały znaczenie kluczowe.

Być może pierwszą cechą pieśni, która przyciąga uwagę badacza, i którą warto podkreślić jest ich wyjątkowo rozbudowana symbolika - symbole zaś według Wojciecha Burszty „stanowią najbardziej trwały element kontinuum kultury, są istotnym elementem jej pamięci i przenoszą sens z jednej warstwy kultury do drugiej, $[\ldots]$ są odbiciem rzeczywistości, objawiają coś podstawowego, starają się ujawnić początek, genezę zjawisk i zawrzeć całościowy obraz świata, [...] oddają istotę funkcjonowania czlowieka w kulturze. Dotyczy to w równej mierze [...] «kultury wysokiej» $\mathrm{i}$ «kultury ludowej»»" Idąc dalej, pieśni są materiałem interesującym i cennym dla współczesnego filologa nie tylko dlatego, że ,przynosiły [...] próbę odpowiedzi na jakże istotne, nurtujące wszystkich pytania o rzeczy ostateczne, które pozostały wszak aktualne i dziś" ", lecz także ze względu na fakt, iż w perspektywie najbliższych kilkunastu lat może zabraknąć najważniejszego ich źródła - osób kultywujących tradycję, dbających o ciągłość przekazu ustnego. Już w 1986 roku Kolbuszewski podkreślał, że jest to ważny sygnał dla badaczy kultury ludowej ${ }^{6}$. Sowietyzacja Europy Środkowo-Wschodniej skutecznie wyjałowiła kulturę ludową, w zamian wprowadzając obowiązkowy socrealizm. Masowe pieśni pracy zastąpiły te śpiewane od wieków, a wędrowni lirnicy i bandurzyści, którzy pozwalali sobie na wykonywanie satyrycznych przyśpiewek o Stalinie i lamenty o głodzie w latach kolektywiza-

\footnotetext{
${ }^{1}$ P. Grochowski, Dusza z ciała wyleciała, „Wędrowiec” 2001, Nº1, s. 19.

2 J. Kolbuszewski, Polska pieśń pogrzebowa. Prolegomena, „Konteksty” 1986, t. 40, s. 52.

${ }^{3}$ Tamże, s. 54.

${ }^{4}$ W. Burszta, Antropologia kultury, Zysk i S-ka, Poznań 1998, s. 115-116.

${ }^{5}$ P. Grochowski, Dusza z ciała..., s. 21.

${ }^{6}$ J. Kolbuszewski, Polska pieśń pogrzebowa ..., s. 50.
} 
cji, zostali wymordowani - w 1937 roku zorganizowano na Ukrainie „festiwal” ponad 200 niewidomych lirników, po czym zimą wywieziono ich na step i tam pozostawiono $^{7}$. $\mathrm{Z}$ drugiej strony, $\mathrm{w}$,kulturze Zachodu niezmiernie skurczyła się i zindywidualizowała sfera rytualno-symboliczna. Mówi się nawet, że żyjemy jedynie na gruzach dawnego, całościowego sensu, że bogaty obszar mitologii kultury stal się wyłącznie archiwum pamięci”. . Rozwój technologiczny, widoczny i na wsi, przyśpieszył proces zanikania pieśni - by usłyszeć muzykę, wystarczyło nastawić odbiornik radiowy na odpowiednie fale. Do listy czynników sprzyjających zanikowi zwyczaju śpiewu Kolbuszewski dodaje jeszcze urbanizacyjną dezintegrację życia ${ }^{9}$. Rozpowszechnienie się druku doprowadziło do marginalizacji roli przekazu ustnego. Źródła pisane nie wymagały bowiem ciągłego odnawiania danej treści, przekazywania jej osobiście z pokolenia na pokolenie, angażowania dużej ilości osób, co było specyficzne dla kultury niższej, a więc i społeczności tradycyjnych ${ }^{10}$. W związku z powyższymi uwarunkowaniami historycznymi ostatnie osoby, które pamiętają pieśni jako nieodłączny element życia codziennego, to najczęściej te urodzone w latach 40-tych. Interesującym czyni to zagadnienie nie tylko zanikający charakter pieśni, ale także stosunkowo późne odkrycie ich jako materiału badawczego. Nastąpiło ono dopiero w XIX wieku, na fali tendencji romantycznych ${ }^{11}$. W tym okresie materiały dotyczące ludu zbierała między innymi grupa badaczy skupionych wokół Oskara Kolberga. Zapisami z owych badań posiłkuje się dziś znaczna część naukowców zajmująca się zagadnieniem kultury ludowej. Można więc stwierdzić, że folkloryści i filologowie badający pieśni pracują nad materiałem chronologicznie ograniczonym, zebranym głównie w przeciągu ostatnich 150-200 lat. Oczywiście nie jest to równoznaczne $\mathrm{z}$ tym, że wcześniej kultura śpiewu ludowego nie istniała sięga ona swoimi korzeniami czasów dużo wcześniejszych, przedchrześcijańskich.

W tym kontekście chciałbym wskazać na jeden z ciekawszych motywów granicznych, często pojawiający się w pieśniach ludowych. Warto rozpocząć w tym miejscu od brzmiącego paradoksalnie, aczkolwiek nie pozbawionego sensu stwierdzenia, że dwoma najbardziej podobnymi do siebie obrzędami z cyklu rodzinnego są pogrzeb i ślub ( $w$ efekcie powoduje to pojawienie się w pieśniach motywu śmierci

${ }^{7}$ P. Dahlig, Śpiewacy wędrowni, lirnicy i ich repertuar jako odwzorowanie świata, w: Mika B., Turek K., (red.), Muzyka religijna - między epokami i kulturami, t.1, Wydawnictwo Uniwersytetu Śląskiego, Katowice 2008, s. 15.

${ }^{8}$ W. Burszta, Antropologia ..., s. 115.

${ }^{9}$ J. Kolbuszewski, Polska pieśń pogrzebowa ..., s. 49. Funkcje poszczególnych pieśni były powiązane ze wspólnotą, jaką tworzyły mniejsze społeczności (ze względu na swoją kameralność, najczęściej wiejskie). Miasto z tysiącami mieszkańców nie jest w stanie wygenerować tak ciasnych więzi.

${ }^{10}$ A. Jackowski, Kilka truizmów i refleksji na temat śmierci, kultury ludowej $i$ sposobu patrzenia na jej wytwory, ,Konteksty” 1986, t. 40, s. 3.

${ }^{11}$ A. Bracki, Stowiańskie pieśni ludowe. Problem rozumienia tekstu, http://dspace.nbuv.gov.ua/ bitstream/handle/123456789/77916/135-Bracki.pdf?sequence=1 (28.02.2020), s. 1 . 
przez zaślubiny). Wielu badaczy zauważa wyraźne ich podobieństwo. Jurij Kruglow pisał w następujący sposób: «B свадебной поэзии, [...] выделяется целая группа песен, которая по своему эмоциональному содержанию ничем не отличается, например, от похоронных причитаний» ${ }^{12}$, zaś Albert Bajburin i Georgij Lewinton swój artykuł rozpoczęli następującym sformułowaniem: «отдельные сходные черты свадебного и погребального обрядов, столь многочисленны, что простое их коллекционирование превращается в задачу слишком легкую, а сколько-нибудь полная систематизация - в слишком трудную» ${ }^{13}$. Owo podobieństwo, ale już na kanwie literatury pięknej, zauważyła również rosyjska badaczka Anna Kolosowa, której artykuł «...Не свадьба это была, а похороны»: элементы погребальной обрядности в повести Н.С. Лескова «Житие одной бабы»» ${ }^{14}$ ukazał się w 2018 roku. Chciałbym, posiłkując się rezultatami własnych badań, uzupełnić ten ciekawy tekst o „ślady”, które można znaleźć w utworach tradycyjnych, wskazując tym samym na ich wartość praktyczną, nośność i przydatność w obszarze badań literaturoznawczych.

Autorka, analizując obraz głównej bohaterki tytułowego utworu Leskowa, a także sposób przedstawienia jej zamążpójścia, dochodzi do takich samych wniosków, jak cytowani wcześniej badacze - obrzęd zaślubin w wielu wymiarach bardziej przypomina ostatnie pożegnanie, niż (jak to postrzegane jest dzisiaj) radosny moment $\mathrm{w}$ życiu. Jako jeden $\mathrm{z}$ elementów potwierdzających to podobieństwo wymienia scenę wywróżenia Nastii szybkiego zamążpójścia, w reakcji na które bohaterka staje się „blada jak śmierć” ${ }^{15}$. Tak, wydawałoby się, niezrozumiałą reakcję dziewczyny rozjaśnia nieco fragment z publikacji o rosyjskich pieśniach obrzędowych, mówiący o tym, że rezultatem niektórych ludowych wróżb mogło być nadchodzące właśnie wesele lub śmierć: «Вечером в сенях на полке или подоконнике кладут столько кусочков хлеба, сколько человек в семье, причем каждый кусок назначают определенному лицу. Утром в Новый год кусочки осматривают. Чьего кусочка не окажется, тот умрет в этот год, а если этот кусок девушки, то она выйдет замуж» ${ }^{16}$. Widać więc wyraźną bliskość obu rezul-

${ }^{12}$ Ю.Г. Круглов, Русские обрядовые песни, Высшая школа, Москва 1989, с. 157.

${ }^{13}$ А.К. Байбурин, Г.А. Левинтон, Похороны и свадьба // Иванов В, Невская Л. (ред.), Исследования в области балто-славянской духовной культуры. Погребальный обряд, Наука, Москва 1990, c. 64.

${ }^{14}$ А.Д, Колосова, «...Не свадьба это была, а похороны»: элементы погребальной обрядности в повести Н.С. Лескова «Житие одной бабы» // Снигирева, Т.А., Назарова, Л.А., Граматчикова, Н.Б., Зырянов, О.В., Матвеева, Ю.В., Пращерук, Н.В., Меньщикова, А.М., (ред.), INITIUM. Художественная литература: опыт современного прочтения, Издательство Уральского федерального университета им. первого Президента России Б.Н. Ельцина, Екатеринбург 2018, с, 75-82.

${ }^{15}$ Там же, с. 77.

${ }^{16}$ В.И. Жекулина, А.Н. Розов, Народные обряды и обрядовая поэзия, Современник, Москва 1989 , с. 602. 
tatów i obu materii. Dalej w swoim artykule Kolosowa cytuje wykrzyczane matce słowa Nastii:

Матушка моя родимая! <...> Матушка, матушка! Зачем же ты меня выдала замуж? Иль я тебя не почитала, не берегла тебя, не смотрела за твоей старостью? [...] Погубили мою жизнь; продали мое тело, и душеньку продадут. Выпнули на позор, на муку, да меня ж упрекают, на меня ж плачутся ${ }^{17}$.

Uderza wręcz niesamowite podobieństwo wykrzyczanych słów do treści i formy lamentów pogrzebowych (potwierdzając tym samym tezę Kruglowa), na przykład ukraińskich: «Ой мамо, мамо, голубко! Ей, нащо ви мене покинули? Ой з ким я буду христосоватьця? Ой хто ж вам там яєчко подасть? Ой мамочко, мамочко» ${ }^{18}$, czy poleskich:

Ой матко ж моя, порадко! Ой куда (чого) ж ти напроців лєта влєтаєш? Ой чого ж ти напроців лєта уцєкаєш? [...] Ой матко моя, порадко! Ой заговори ж напроців мене. Ой за што ж ти на мене загніваласа? Што ж ти не хоч, матко, зо мною говоріці? ${ }^{19}$.

Jeszcze innym z omawianych przez Kolosową aspektów, przy którym można by było sięgnąć do rezerwuaru badań nad pieśniami jest fragment opisujący szykowanie Nastii do ślubu. Badaczka zauważa: «Утром свадебного дня Настю одевают «к венцу», поют песни, расплетают девичью косу, что отсылает нас не только к этапу свадебного обряда (обряжание невесты), но и к обычаю хоронить молодых девушек в свадебном обличии (обряжание покойника)» ${ }^{20}$. I tak, u Kolberga, klasyka polskich badań nad pieśniami znaleźć można słowa dodatkowo potwierdzające tezę rosyjskiej badaczki: „W Słupi pod Rawiczem, gdy młodzieniec lub dziewka umrze, rodzice ich w kilka dni potem, wyprawiając stypę, proszą sąsiadów, jakoby (jak się wyrażają) na wesele nieboszczyka. - Wiadomo, że dziewkę i parobka chowają w stroju weselnym (a głównie we wieńcach), na który

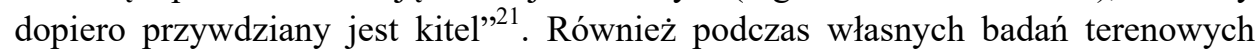
uzyskałem informację o tym, że w Wielkopolsce (Gostyń) jeszcze dekadę temu, gdy umierała młoda osoba, ciało ubierano ,jak do ślubu"22. Chciałbym jeszcze w tym miejscu rozwinąć jedynie zasygnalizowany przez Kolosową we wstępie, a, jak uważam, ważny aspekt porównawczy omawianego zagadnienia. Porównując te dwa obrzędy,

${ }^{17}$ А.Д, Колосова, «...Не свадьба..., с. 77.

${ }^{18}$ А. Іваницький, Украӥнський обрядовий фольклор західних земель. Регіональна музична антологія, Нова Книга, Вінниця 2012, с. 570.

${ }^{19}$ Там само, с. 576.

${ }^{20}$ А.Д, Колосова, «...Не свадьба..., с. 79.

${ }^{21}$ O. Kolberg, Dzieła wszystkie, t. 10, Wydawnictwo Polskiego Towarzystwa Ludoznawczego, Wrocław-Poznań 1963, Reedycja fotooffsetowa, pierwodruk: Kraków 1876, s. 218.

${ }^{22}$ Informacja od Krystyny Woźniak, ur. 1936, Kalisz. 
można zauważyć, że w obu przypadkach dochodzi do wydzielenia konkretnej jednostki z grupy (panna młoda/pan młody, zmarła/zmarły), przeprowadzenia jej przez okres przejściowy (w przypadku ślubu - wszystkie czynności od swatów do wesela, w przypadku pogrzebu - od pomocy przy śmierci do około 40 dnia po pogrzebaniu ciała) do oczekiwanego stanu końcowego, gdzie zmienia się status osoby znajdującej się w centrum obrzędu (panna - małżonka - matka, żywy człowiek - zmarły/przodek). Zmienia się również status uczestników obrzędu (matka - babka - teściowa, ku$\mathrm{ma} /$ marszałek i im podobne funkcje nadawane podczas ślubu, żona - wdowa, córka - sierota, młodsze pokolenie staje się starszym pokoleniem, prowadzący ceremonię reprezentuje zmarłego mówiąc w jego imieniu i inne). Osoba, która przejdzie przez obrzęd ślubu/pogrzebu, nie jest już stałą częścią poprzedniego kolektywu (najbliższego grona rodziny), co przejawia się w tym, że odwiedza go, posiadając status gościa (córka 3 dzień po ślubie, zmarły podczas dziadów jesiennych) ${ }^{23}$.

Możliwości sięgania do omawianych rezerwuarów podczas analizy literatury jest oczywiście o wiele więcej i wykraczają one poza obrazy z kategorii obrzędowości. Innymi, mniej oczywistymi tropami mogłyby być utwory współczesnych autorów. Analiza tekstów dziadowskich pieśni pogańsko-sakralnych (takie połączenie jest zupełnie naturalne dla społeczeństw chrystianizowanych, nakładających warstwę sakralną na wcześniejsze systemy wierzeń) może przynieść odpowiedzi na pytania zadawane przy analizie fenomenu powstawania sekt, podobnych do tych z Zatopionej arki Aleksieja Warłamowa czy Uniewinnienia Dmitrija Bykowa. Może być ona pomocna również przy zrozumieniu natury takich postaci jak wiejscy zamawiacze/szeptuni oraz starcy-cudotwórcy mieszkający w leśnych pustelniach rodem z Laura Jewgienija Wodolazkina. Równie ciekawym i aktualnym zagadnieniem, podnoszonym póki co głównie oddzielnie w twórczości muzycznej i literackiej, jest również kwestia emancypacji kobiet, zwłaszcza w poprzednim stuleciu. Ze strony muzycznej materiał mogłyby dostarczyć utwory zespołów/projektów łączących współczesne aranżacje z tekstami tradycyjnych pieśni o kobietach. Tego typu twórcze inicjatywy podejmowały takie zespoły jak ukraińskie Дах Дотерс (Rozy / Donbass), Тимчуки (swoisty manifest feministyczny Сама иду по каменю) czy polskie projekty Chór czarownic oraz Minimal blood. Jak można przeczytać na stronie dystrybutora ostatniego $\mathrm{z}$ wymienionych, są to „historie prawdziwe i te mieszające świat realny z magicznym, które niegdyś służyły zapewne wzmocnieniu moralności. Czytane przez pryzmat współczesności opowiadają o wielowątkowości losów kobiety, o ich wrażliwości i emocjonalności, niemocy ale i poczuciu sprawstwa, miłości i odrzuconych uczuciach" ${ }^{24}$. Wymienione powyżej przykłady to zaledwie część źródeł, z których można czerpać podczas próby zestawienia utworów tradycyjnych

\footnotetext{
${ }^{23}$ Ю.Г. Круглов, Русские обрядовые песни..., с. 68-70.

${ }^{24} \mathrm{https}: / /$ wsm.serpent.pl/sklep/albumik.php,alb_id,61990,Tradycyjne+piesni+o+kobietach+i+krwi, Minimal+Blood (26.02.20).
} 
z, na przykład, współczesną prozą/poezją/filmem feministycznym takich autorek jak Marija Iwanowna czy Kristina Giepting.

Literatura piękna i twórczość społeczności tradycyjnych wchodzi także w dużo bardziej bezpośrednie korelacje. Jelena Jewkijewskaja, badając saratowskie obrzędy pogrzebowe doszła do wniosku, że teksty pieśni służących do „odśpiewywania” zmarłego tworzą

[...] весьма пестрый и разнородный по происхождению круг текстов, которые (за исключением канонических) первоначально вовсе не были предназначены для погребальных целей. Однако будучи вписанными в структуру отпевания, они образовали смысловое единство, подчиняясь общей прагматической задаче правильно проводить умершего в «иной мир» [...]. Второй механизм, который «втягивает» тот или иной текст в «отпевальную» традицию, - не только и не столько тема смерти, сколько наличие ключевых слов и мотивов, выполняющих роль маркеров и позволяющих переосмыслить текст в нужном русле, даже если первоначально он имел совершенно другой смысл. К числу таких маркеров относятся: смерть, душа, грех, молитва, расставание/разлука, слезы, скорбь, а также мотивы расставания души с телом, раскаяния в грехах, Божьего суда и др. ${ }^{25}$

Podążając za postawioną tezą, badaczka odnalazła podczas swoich analiz utwory autorstwa znanych pisarzy rosyjskich, ,przechwyconych” i zmienionych przez lud, jak na przykład wiersz Gogola $К$ тебе, о Мати Пресвятая, дерзаю вознести свой глас.

Również w odwrotnym procesie, motywy z ludowych pieśni do swojej twórczości przenosili liczni wschodniosłowiańscy i polscy pisarze, tacy jak Taras Szewczenko (wiersze o kobiecej niedoli z tomu Кобзар), Michaił Lermontow (Казачья кольбельная песня) czy Stanisław Vincenz (znaczna część pierwszego tomu $\mathrm{Na}$ wysokiej połoninie).

Na koniec chciałbym podkreślić jeszcze, że analiza pieśni mogłaby okazać się intelektualnie płodnym narzędziem również dla reprezentantów dziedzin spoza obrębu literaturoznawstwa. Lingwiści odnajdą w nich klisze zawierające obraz żywego języka, gwar czy oboczności, na podstawie których można obserwować jak język ewoluuje wraz z przekazaniem pieśni kolejnemu pokoleniu, jak się zmienia wraz ze zmianą szerokości geograficznej, jakie pojawiają się wariantywności. Dla historyków mogą stanowić kolejne źródło przekazu ustnego - na przykład pieśni buntu chłopskiego rejestrowały nastroje społeczne w danym okresie, a dzięki nowiniarskim, jak ta o Janku Siegiedzie, zachowały się prawdziwe wydarzenia poruszające ówczesnych odbiorców. Religioznawcy odnajdą w nich wyobrażenia społeczności tradycyjnych na tematy eschatologiczne i podobne zagadnienia natury teologicznejjako przykład warto w tym miejscu wymienić utrzymaną w tym nurcie, znakomitą

\footnotetext{
${ }^{25}$ Е. Левкиевская, Литературные тексты в традиционном погребальном обряде украинцев саратовской области, „Przegląd Rusycystyczny” 2019, №1, c. 153-4.
} 
pracę Magdaleny Zowczak. Te trzy obszary nauki oczywiście nie wyczerpują obszernej listy dziedzin, którą można by było długo jeszcze w podobny sposób powiększać o kolejne pozycje. Mam nadzieję, że niniejszy artykuł zachęci reprezentantów różnych obszarów naukowych do badań nad tekstami pieśni tradycyjnych i wzbogacenia tym samym owej listy wynikami swoich analiz.

\section{Bibliografia}

Bajburin, Al'bert Kashfullovich. Levinton, Georgij Ahillovich. 1990. „Pohorony i svad'ba.” W zbiorze: Ivanov, Vjacheslav. Nevskaja, Ljudmila. (red.). Issledovanija v oblasti balto-slavjanskoj duhovnoj kul'tury. Pogrebal'nyj obrjad. Moskva: Nauka. [Байбурин, Альберт Кашфуллович. Левинтон, Георгий Ахиллович. „Похороны и свадьба.” Исследования в области балто-славянской духовной культуры. Погребальный обряд. Ред. Иванов, Вячеслав. Невская, Людмила. Москва: Наука, 1990].

Bracki, A. 2020. „Słowiańskie pieśni ludowe. Problem rozumienia tekstu”. <http://dspace.nbuv.gov. ua/bitstream/handle/123456789/77916/135-Bracki.pdf?sequence=1>.

Burszta, W. 1998. Antropologia kultury. Poznań: Zysk i S-ka.

Dahlig, P. 2008. „Śpiewacy wędrowni, lirnicy i ich repertuar jako odwzorowanie świata.” W zbiorze: Mika, B. i K. Turek. (red.). Muzyka religijna - między epokami i kulturami. Vol. 1. Katowice: Wydawnictwo Uniwersytetu Śląskiego. 13-21.

Grochowski, P. 2001. „Dusza z ciała wyleciała.” Wędrowiec 1. 17-23.

Ivanyc'kyj, Anatolij. 2012. Ukrayins'kyj obryadovyj fol'klor zaxidnyx zemel'. Rehional'na muzychna antolohiya. Vinnycya: Nova Knyha. [Іваницький, Анатолій. Український обрядовий фольклор західних земель. Регіональна музична антологія. Вінниця: Нова Книга, 2012].

Jackowski, A. 1986. „Kilka truizmów i refleksji na temat śmierci, kultury ludowej i sposobu patrzenia na jej wytwory." Konteksty 40. 3-8.

Kolberg, O. 1963. Dzieła wszystkie. Vol. 10. Wrocław-Poznań: Wydawnictwo Polskiego Towarzystwa Ludoznawczego.

Kolbuszewski, J. 1986. „Polska pieśń pogrzebowa. Prolegomena.” Konteksty 40. 49-56.

Kolosova, Anna Dmitrievna. „'...Ne svad'ba jeto byla, a pohorony': jelementy pogrebal'noj obrjadnosti v povesti N.S. Leskova 'Zhitie odnoj baby'." INITIUM. Hudozhestvennaja literatura: opyt sovremennogo prochtenija. Ed. Snigireva, Tat'jana Aleksandrovna. Nazarova, Larisa Aleksandrovna. Gramatchikova, Natal'ja Borisovna. Zyrjanov, Oleg Vasil'evich. Matveeva, Julija Vladimirovna. Prashheruk, Natal'ja Viktorovna. Soboleva, Larisa Stepanovna. Turysheva, Ol'ga Naumovna. Men'shhikova, Anna Manasovna., Ekaterinburg: Izdatel'stvo Ural'skogo federal'nogo universiteta im. pervogo Prezidenta Rossii B.N. El'cina, 2018. [Колосова, Анна Дмитриевна. „‘...Не свадьба это была, а похороны': элементы погребальной обрядности в повести Н.С. Лескова 'Житие одной бабы'." INITIUM. Художественная литература: опьт современного прочтения. Ред. Снигирева, Татьяна Александровна. Назарова, Лариса Александровна. Граматчикова, Наталья Борисовна. Зырянов, Олег Васильевич. Матвеева, Юлия Владимировна. Пращерук, Наталья Викторовна. Соболева, Лариса Степановна. Турышева, Ольга Наумовна. Меньщикова, Анна Манасовна., Екатеринбург: Издательство Уральского федерального университета им. первого Президента России Б.Н. Ельцина, 2018].

Kruglov, Jurij Georgievich. 1989. Russkie obrjadovye pesni. Moskva: Vysshaja shkola. [Круглов, Юрий Георгиевич. Русские обрядовые песни. Москва: Высшая школа, 1989]. 
Levkievskaja, Elena. 2019. „Literaturnye teksty v tradicionnom pogrebal'nom obrjade ukraincev saratovskoj oblasti.” Przegląd Rusycystyczny 1. 149-160. [Левкиевская, Елена. „Литературные тексты в традиционном погребальном обряде украинцев саратовской области.” Przeglad Rusycystyczny 2019 no. 1. 149-160].

Zhekulina, Valentina Ivanovna. Rozov, Aleksandr Nikolaevich. 1989. Narodnye obrjady i obrjadovaja pojezija. Moskva: Sovremennik. [Жекулина, Валентина Ивановна. Розов, Александр Николаевич. Народные обряды и обрядовая поэзия. Москва: Современник, 1989]. 